\title{
Prediksi Pathloss Berbasis Model Perambatan Okumura-Hata dan Interpolasi Spline pada Daerah Beredaman Hujan Tinggi
}

\author{
Rudy $^{1}$, Syahfrizal Tahcfulloh ${ }^{2}$ \\ 1,2 Jurusan Teknik Elektro, Fakultas Teknik-Universitas Borneo Tarakan \\ Jl. Amal Lama No.1, Tarakan-Kalimantan Utara, 77123 \\ rudy@borneo.ac.id,rizalubt@gmail.com
}

\begin{abstract}
Abstrak - Artikel ini bertujuan untuk menyajikan model propagasi jaringan GSM di Tarakan yang beredaman hujan tinggi untuk memprediksi pathloss dengan berbasiskan model Okumura-Hata dan Interpolasi Spline. Penelitian ini dilakukan untuk daerah perkotaan, karena data pengukuran yang diperoleh dari PT Telkomsel berlokasi di daerah perkotaan. Penelitian ini dapat dijadikan acuan untuk perencanaan jaringan GSM yang lebih baik untuk wilayah kota, karena terdapat modifikasi model pathloss OkumuraHata dengan menyelidiki variasi pathloss antara nilai-nilai yang diukur dan diprediksi sehingga menghasilkan nilai MSE yang dianjurkan serta disesuaikan dengan kondisi iklim di Tarakan yang beredaman hujan relatif tinggi. Kemudian, dengan Interpolasi Spline akan dilakukan prediksi pathloss menggunakan data hasil pemodelan termodifikasi. Oleh karena itu, model memberikan perbedaan yang signifikan di daerah terbuka yang memungkinkan adanya modifikasi. Kesalahan yang diminimalkan dengan mengurangi MSE sebesar 15.3 dB dihitung dari Model Okumura-Hata untuk daerah terbuka. Persamaan modifikasi juga diverifikasi untuk sel lain di daerah di Tarakan dan memberikan hasil yang dapat diterima.
\end{abstract}

Kata kunci - Pathloss, Perambatan Okumura-Hata, Interpolasi Spline, Redaman Hujan.

\section{PENDAHULUAN}

Pertumbuhan komunikasi bergerak saat ini sangatlah pesat, karena memungkinkan adanya penyebaran teknologi yang lebih luas. Secara historis, pertumbuhan di bidang komunikasi bergerak kini cenderung lambat, dibandingkan dengan kemajuan teknologi [1]-[2]. Kebutuhan akan kualitas layanan yang tinggi dan jaringan berkapasitas tinggi, cakupan baik telah menjadi tuntutan yang penting. Oleh karena itu untuk desain cakupan yang lebih akurat dari jaringan selular modern maka pengukuran kekuatan sinyal harus dipertimbangkan dalam rangka memberikan cakupan area layanan yang efisien dan dapat diandalkan. Artikel ini membahas perbandingan antara teori dan model propagasi empiris. Model empiris yang paling banyak digunakan untuk komunikasi bergerak dengan data pengukuran dan diakui oleh International Telecommunication Union (ITU) adalah Model Okumura-Hata [3].

Konsep komunikasi selular adalah terobosan besar dalam memecahkan masalah kongesti dan kapasitas pengguna dengan menawarkan kapasitas layanan yang tinggi dengan alokasi spektrum yang terbatas tanpa ada perubahan teknologi utama. Konsep komunikasi selular adalah sistem dimana satu pemancar daya tinggi (sel besar) diganti dengan banyak pemancar daya rendah (sel kecil). Area yang dilayani oleh pemancar disebut sel. Setiap pemancar berdaya pancar kecil, juga disebut base transceiver station
(BTS) menyediakan cakupan layana untuk hanya sebagian kecil dari daerah layanan. Hilangnya daya yang terjadi dalam proses transmisi antara BS dan mobile station (MS) dikenal sebagai pathloss yang dipengaruhi terutama oleh ketinggian antena, frekuensi pembawa dan jarak antara Pemancar dan Penerima. Pada frekuensi yang lebih tinggi nilai pathloss yang diberikan relatif besar, sehingga diperlukan sel-sel lainnya untuk menutupi daerah tertentu. Satu BTS dengan lainnya saling menutupi dalam berbagi saluran. Sehingga saluran yang tersedia digunakan oleh sejumlah kecil dari BTS tetangga. BTS yang berdekatan berbagi dalam kelompok saluran sehingga interferensi antara BTS atau interaksi antara sel-sel dapat diminimalkan. Untuk permintaan layanan yang meningkat maka jumlah BTS dapat ditingkatkan, sehingga memberikan tambahan kapasitas layanan tanpa adanya peningkatan spektrum radio. Gagasan utama untuk sistem selular modern adalah adanya kemungkinan melayani pelanggan yang jumlahnya tidak terbatas tersebar di daerah terbatas hanya menggunakan sejumlah saluran, berdasarkan prinsip efisiensi penggunaan kanal [2].

\section{Model PROPAGASI}

Model propagasi dibagi menjadi dua tipe dasar; yaitu: model propagasi teoritis seperti propagasi ruang bebas dan model propagasi ground plane, dan model propagasi empiris seperti model propagasi seluler yaitu model pengukuran Okumura-Hata.

\section{A. Model Propagasi Free Space}

Dalam ruang bebas, gelombang elektromagnetik dari pemancar tidak terpantulkan atau diserap. Propagasi ideal ini menunjukkan bahwa adanya besar radiasi yang sama ke segala arah dari sumber radiasi dan propagasi untuk jarak tak terbatas tanpa adanya penyusutan sinyal. Penyebaran daya atas daerah cakupan yang besar menyebabkan penyusutan daya.

$$
P_{d}=P_{t} / 4 \pi d^{2}
$$

Dimana $P_{t}$ adalah daya yang ditransmisikan dalam $\mathrm{W} / \mathrm{m}^{2}$ dan $P_{d}$ adalah daya pada jarak $d$ dari antena. Jika elemen peradiasi memancarkan daya tetap dan tersebar seperti bola yang mengembang.

Bila kerapatan fluks daya pada setiap titik telah teridentifikasi pada jarak tertentu dari radiator maka daya yang diterima pada antena penerima yang berlokasi pada titik ini akan dapat dihitung. Rumus untuk menghitung tangkapan daya antena yang efektif ditunjukkan dalam persamaan (2) dan (3). Daya total yang ditangkap oleh 
antena pada jarak $d$ bergantung pada: (a) permukaan tangkap dari antena penerima $\left(A_{o}\right)$, (b) panjang gelombang yang diterima sinyal $(\lambda)$, dan kerapatan fluks daya $(c)$ pada antena penerima $P_{d}$.

Luas efektif $\left(A_{e}\right)$ antena isotropik yaitu

$$
A_{e}=\lambda^{2} / 4 \pi
$$

Sedangkan daya yang diterima adalah

$$
P_{r}=P_{d} \times A_{e}=P_{t} \times \lambda^{2} /(4 \pi d)^{2}
$$

Pathloss dapat dihitung dengan

$$
L_{p}=P_{t}-P_{r}
$$

Ketika mensubstitusi persamaan (3) dalam persamaan (4), mengganti $(\lambda$ (dalam $\mathrm{km})=0,3 / f_{c}($ dalam $\left.\mathrm{MHz})\right)$ dan disederhanakan menghasilkan formula pathloss untuk saluran free space yang dinyatakan dalam persamaan (5) :

$$
L_{p}(d B)=32.5+20 \log _{10}(d)+20 \log _{10}\left(f_{c}\right)
$$

\section{B. Model Propagasi Plane Earth}

Model propagasi ruang bebas tidak mempertimbangkan dampak dari propagasi di atas tanah. Ketika gelombang radio merambat di atas tanah maka beberapa daya pancar akan terpantulkan kemudian baru diterima oleh penerima. Model propagasi yang memperhitungkan pengaruh pantulan dinamakan model propagasi Plane Earth. Model ini masih lebih baik karena merupakan karakteristik sebenarnya dari gelombang radio propagasi atas tanah. Model ini mmperhitungkan sinyal yang diterima berupa jumlah dari sinyal langsung dan sinyal hasil pantulan. Parameter yang relevan termasuk ketinggian antena, panjang lintasan, frekuensi operasi dan koefisien refleksi dari bumi. Koefisien ini akan bervariasi sesuai dengan jenis medan (misalnya air, padang pasir, tanah basah dll). Persamaan pathloss untuk model propagasi Plane Earth diilustrasikan dalam persamaan (6).

$$
L_{p e}(d B)=40 \log _{10}(d)-20 \log _{10}\left(h_{1}\right)-20 \log _{10}\left(h_{2}\right)
$$

Dimana $d$ merupakan panjang lintasan dalam meter dan $h_{1}$ dan $h_{2}$ berturut-turut adalah ketinggian antena pada BS dan MS. Model ini tidak tepat untuk sistem GSM karena tidak mempertimbangkan refleksi dari bangunan, beberapa propagasi atau efek difraksi. Selain itu, jika ketinggian ponsel berubah maka pathloss diprediksi juga akan berubah.

\section{Model Propagasi Selular}

Dua model propagasi dasar tersebut akan membutuhkan pengetahuan rinci tentang lokasi, dimensi dan parameter konstitutif setiap pohon, bangunan, dan fitur medan di daerah yang akan dibahas. Ini terlalu rumit dan tidak praktis dan akan menghasilkan perhitungan yang tidak perlu. Salah satu cara yang tepat untuk menghitung propagasi adalah melalui model empiris. Ada berbagai model prediksi empiris di antaranya adalah Model Okumura-Hata, Model Cost 231Hata, Model Cost 231 Walfisch-Ikegami, dan Model Sakagami- Kuboi. Model ini tergantung pada lokasi, rentang frekuensi dan jenis pemukiman seperti perkotaan, sub-urban dan pedesaan.

\section{Pengukuran Okumura}

Pengukuran Okumura dilakukan untuk berbagai tipe perkotaan, frekuensi, tinggi pemancar, dan daya pemancar. Hal ini menyatakan bahwa kekuatan sinyal menurun pada jarak yang jauh dibandingkan dengan jarak yang diperkirakan oleh free space loss [3]-[5]. Data daya sinyal pengukuran diperoleh dari PT.Telkomsel Tarakan.

\section{E. Model Propagasi Hata}

Model Hata didasarkan pada hasil uji lapangan Okumura dan digunakan untuk memprediksi pathloss dengan berbagai jenis kondisi wilayahnya. Keterbatasan pada Model Hata adalah berkerja pada frekuensi pembawa $150 \mathrm{Mhz}$ sampai $1500 \mathrm{Mhz}$, jarak dari BS berkisar dari $1 \mathrm{~km}$ sampai $20 \mathrm{~km}$, ketinggian antena BS $\left(h_{b}\right)$ berkisar antara $30 \mathrm{~m}$ sampai 200 m dan tinggi antena MS $\left(h_{m}\right)$ berkisar antara $1 \mathrm{~m}$ sampai 10 m. Hata menciptakan sejumlah model pathloss untuk masing-masing lingkungan perkotaan, pinggiran kota dan terbuka, seperti yang diilustrasikan dalam persamaan (7-9).

Pathloss untuk daerah perkotaan:

$$
\begin{aligned}
L_{p}(\text { urban })= & 69.55+26.16 \log _{10}\left(f_{c}\right)-13.82 \log _{10}\left(h_{b}\right)-a\left(h_{m}\right) \\
& +\left(44.9-6.55 \log _{10}\left(h_{b}\right)\right) \log _{10}(d) \\
a\left(h_{m}\right)= & \left(1.1 \log _{10}\left(f_{c}\right)-0.7\right) h_{m}-\left(1.56 \log _{10}\left(f_{c}\right)-0.8\right)
\end{aligned}
$$

Pathloss daerah subkota:

$$
L_{p}(\text { suburban })=L_{p}(\text { urban })-2\left(\log _{10}\left(f_{c} / 28\right)\right)^{2}-5.4
$$

Pathloss untuk daerah lain:

$$
\begin{gathered}
L_{p}(\text { open country })=L_{p}(\text { urban })-4.78\left(\log _{10}\left(f_{c}\right)\right)^{2} \\
+18.33 \log _{10}\left(f_{c}\right)-40.94
\end{gathered}
$$

Model Hata tidak sesuai untuk perencanaan mikro dimana antena di bawah ketinggian atap dan frekuensi pembawa maksimum adalah $1500 \mathrm{MHz}$. Hal ini tidak berlaku untuk sistem $1800 \mathrm{MHz}$ dan $1900 \mathrm{MHz}$.

\section{HASIL DAN PEMBAHASAN}

Untuk menghasilkan pengukuran level sinyal daya untuk downlink dan uplink di daerah cakupan pada sebuah sel di Tarakan. Namun, jalan dari Tarakan dapat dianggap sebagai daerah terbuka dan karena itu persamaan (7)-(9) yang digunakan pada model Okumura-Hata. Setelah menentukan pathloss dari pengukuran untuk setiap jarak maka penelitian ini dilakukan di dalam rangka untuk membuat perbandingan antara nilai-nilai eksperimental dan teoritis dan hasilnya ditunjukkan pada Gambar 1.

Dari Gambar 1, hasilnya jelas menunjukkan bahwa pathloss diukur kurang dari prediksi dengan perbedaan bervariasi $4 \mathrm{~dB}$ hingga $20 \mathrm{~dB}$. Namun, ada beberapa alasan yang dapat menyebabkan perbedaan yang signifikan. Pertama-tama, di Jepang ada beberapa daerah hampir memenuhi kondisi daerah terbuka, dan jika ada masih jarang. Karena alasan itu Okumura dipilih untuk daerah perkotaan sebagai standar untuk wilayah terbuka [5]. Selain itu, situasi geografis Jepang berbeda dengan di Tarakan karena perbedaan geografis. Kemudian, mean square error (MSE) dihitung dari nilai pathloss hasil pengukuran dan hasil prediksi oleh model Hata menggunakan persamaan [6] berikut: 


$$
M S E=\sqrt{\left(\sum\left(P_{m}-P_{r}\right)^{2} /(N-1)\right)}
$$

Dimana $P_{m}$ merupakan pathloss hasil pengukuran $(\mathrm{dB}), P_{r}$ pathloss hasil model (dB), dan $N$ adalah jumlah titik data yang diukur.

MSE diperoleh sebesar $15.3 \mathrm{~dB}$ dan masih dalam ambang yang dapat diterima [6]. Oleh karena itu, MSE dikurangi dari persamaan Hata untuk daerah terbuka sehingga menghasilkan persamaan yang dimodifikasi seperti berikut:

$$
\begin{gathered}
L_{p} \text { modified }(\text { open area })=L_{p}(\text { urban })-4.78\left(\log _{10}\left(f_{c}\right)\right)^{2} \\
+18.33 \log _{10}\left(f_{c}\right)-56.26
\end{gathered}
$$

Grafik hasil modifikasi dari persamaan Hata di daerah terbuka ditunjukkan pada Gambar 2 dengan menggunakan persamaan dimodifikasi dan MSE dalam hal ini adalah kurang $6 \mathrm{~dB}$, yang diterima [6].

Untuk memverifikasi bahwa persamaan Hata ini dimodifikasi daerah terbuka (11) dan berlaku untuk daerah terbuka lainnya di Tarakan, data lainnya yang dihasilkan dari PT. Telkomsel untuk sel lain di jalan Tarakan telah digunakan dengan menggunakan Interpolasi Spline. Berdasarkan data praktis, propagasi pathloss dan jarak telah diverifikasi ulang untuk sel lain.

\section{KESIMPULAN}

Pengaruh dari situasi medan diperkirakan pada $900 \mathrm{MHz}$ dianalisis. Hasil sinyal radio pengukuran propagasi untuk area terbuka di Tarakan dibandingkan dengan yang diperkirakan berdasarkan model Okumura-Hata. Namun, model propagasi Okumura-Hata mungkin tidak sepenuhnya tepat untuk propagasi di Tarakan karena terdapat redaman hujan relatif besar di Tarakan. Oleh karena itu, perbaikan lebih lanjut model Okumura-Hata di daerah terbuka telah disarankan. Peningkatan ini dicapai dengan menggunakan mean square error (MSE) antara nilai-nilai pathloss terukur dan terprediksi telah memberikan nilai MSE yang bisa diterima untuk prediksi (11) dan telah diverifikasi untuk sel di daerah lain yang terbuka dan MSE ditemukan $3.21 \mathrm{~dB}$ [6].

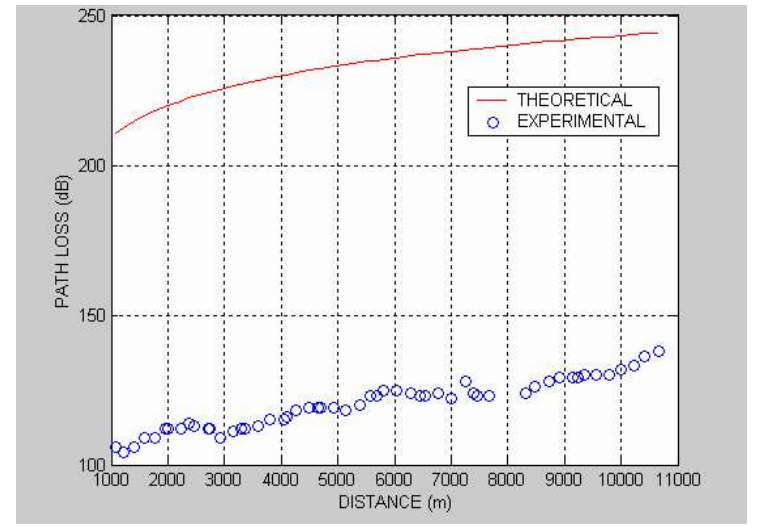

Gambar 1. Pathloss secara teoritis versus pengukuran

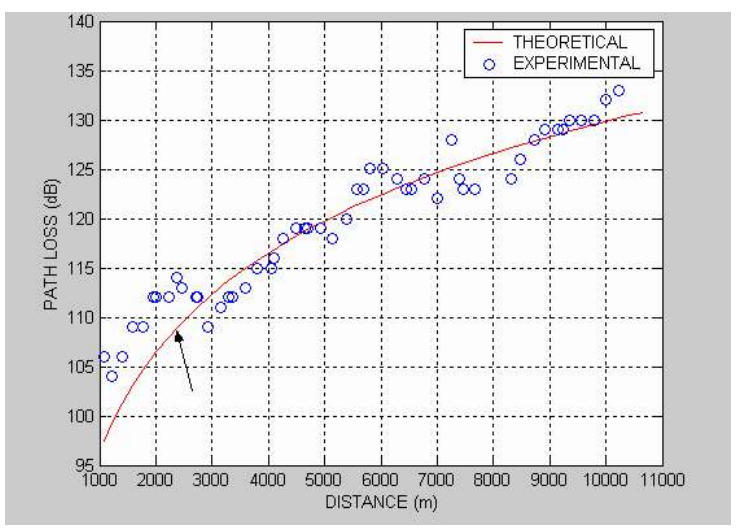

Gambar 2. Grafik hasil persamaan model Hata termodifikasi versus jarak

\section{DAFTAR PUSTAKA}

[1] D. Nobel, "The history of land to mobile radio communications," IEEE Transactions on Vehicular Technology, pp. 1406-1416, May 1962.

[2] V. H. MacDonald, "The cellular concept," The Bell Systems Technical Journal, vol. 58, no. 1, pp. 15-43, January 1979.

[3] A. Medeisis and A. Kajackas, "On the Use of the Universal Okumura-Hata Propagation Predication Model in Rural Areas", Vehicular Technology Conference Proceedings, VTC Tokyo, Vol.3, pp. 1815-1818, May 2000.

[4] R. D. Wilson and R. A. Scholtz, "Comparison of CDMA and Modulation Schemes for UWB Radio in a Multipath Environment", Proceedings of IEEE Global Telecommunications Conference, Vol. 2, Dec 2003.

[5] J. Wu and D. Yuan, "Propagation Measurements and Modeling in Jinan City", IEEE International Symposium on Personal, Indoor and Mobile Radio Communications, Boston, MA, USA, Vol. 3, pp. 1157-1159, 8-11 September 1998.

[6] Z. Nadir, N. Elfadhil, F. Touati, "Pathloss determinat ion using Okumura-Hata model and spline interpolation for missing data for Oman" World Congress on Engineering, IAENG-WCE-2008, Imperial College, London, United Kingdom, 2-4 July,2008. 